\title{
ASIMTOT: JURNAL KEPENDIDIKAN MATEMATIKA
}

Volume 1 Nomor 2, Juni - November 2019, halaman 105 - 110

Tersedia Daring padahttps://journal.unwira.ac.id/index.php/ASIMTOT

\section{PENGARUH MODEL PEMBELAJARAN OPEN-ENDED TERHADAP PRESTASI BELAJAR MATEMATIKA SISWA}

\section{THE EFFECT OF OPEN-ENDED TEACHING MODEL ON MATHEMATICS STUDENT'S LEARNING ACHIEVENTS}

\author{
Renny C. N. Sonbay, Yohana R. Rowa \\ Universitas Katolik Widya Mandira \\ jennysonbay99@gmail.com, yohanarowa@gmail.com,
}

\begin{abstract}
Abstrak: Penelitian ini bertujuan untuk mengetahui bagaimana pelaksanaan model pembelajaran Open-Ended dan pengaruhnya terhadap prestasi belajar matematika siswa pada sub pokok bahasan segiempat di SMPN Kupang Tengah tahun ajaran2018/2019. Penelitian ini dilakukan oleh siswa kelas VII SMPN Kupang Tengah yang berjumlah 21 orang siswa yang dipilih secara acak dari 4 kelas yang tersedia.Instrumen yang digunakan dalam penelitian ini yaitu observasi dan tes prestasi belajar matematika siswa sebayak 3 butir soal berbentuk isian.Teknik analisis data yang digunakan dalam penelitian ini yaitu hasil observasi,hasil wawancara,pencapaian indikator dan uji-t. Berdasarkan hasil observasi, hasil wawancara, dan pencapaian indikator, diperoleh prestasi belajar matematika siswa tergolong sangat baik. Sedangkan berdasarkan perhitungan uji-t menunjukan $t$ hitung $=10,742$ dan $\mathrm{t}$ table $=2,085$ pada taraf signifikani $5 \%$ yang berarti $\mathrm{t}$ hitung $>\mathrm{t}$ tabel, Maka Ho ditolak dan Ha diterima. Sehingga dapat diambil kesimpulan bahwa ada pengaruh yang signifikan pada pengunaan model pembelajaran Open-Ended terhadap prestasi belajar matematika siswa SMP.
\end{abstract}

Kata Kunci: Model pembelajaran pembelajaran Open-Ended, Prestasi belajar

Abstract: This research is aimed to know how the learning model process Open-Ended and the impact of this learning model towards the achievement of Matematics study of students on the sub chapter "Segiempat" at SMPN Kupang Tengah in accademic year 2018/2019. This research is conducted by seventh grade students of SMPN Kupang Tengah. They are 21 students who were elected as randomly from four classes. The instruments are used in this research namely observation and test of achievement of study matematics which number 2 questions in essay form. The techniques of data analysis used are namely the result of observation, interview, indicator of achievement and Uji-t. Based on the result of observation, interview and indicator of achievement can be got that the achievement of the students in learning mathematics are very good. Even based on the Uji-t shown thitung $=10.742$ and t table $=2.085$ on the significant level 5\%. So, Ho is refused and Ha is accepted. So that it can be concluded there is the significant impact of using learning model Open-Ended towards the achievement of study mathematics of students

Key Words: Learning Model Open-Ended, The achievement of study

Cara Sitasi: Sonbay. C.N.S.R., \& Rowa, R. Y., (2019). Pengaruh Model Pembelajaran Open-Ended Terhadap Prestasi Belajar Matematika Siswa. Asimtot: Jurnal Kependidikan Matematika, “1”(“2”), “105 - 110” 
Pendidikan merupakan salah satu faktor penentu dalam upaya meningkatkan sumber daya manusia. Pendidikan selalu mengupayakan kehidupan manusia kearah yang lebih baik dan diperlukan untuk kehidupan di masa yang akan datang. Berbagai upaya telah dilakukan bangsa ini untuk meningkatkan kualitas pendidikan di Indonesia.Salah satu upaya yang dilakukan adalah dengan meningkatkan kualitas pembelajaran yang dilakukan di sekolahsekolah. Kualitas pendidikan dilihat pada proses pembelajaran.

Dalam suatu lembaga pendidikan, keberhasilan proses pembelajaran dapat dilihat dari prestasi belajar yang dicapai oleh siswa. Skinner melalui Teori Operant Conditing dan salah satu hukum belajar dari Thorndike "Law of Effect" (Anurrahman, 2011, hal. 112)menyebutkan pengenalan seseorang terhadap prestasi belajarnya adalah penting, karena dengan mengetahui hasilhasil yang sudah dicapai maka siswa akan lebih berusaha meningkatkan prestasi belajarnya. Dengan demikian peningkatan prestasi belajar dapat lebih optimal karena siswa tersebut merasa termotivasi untuk meningkatkan prestasi belajar yang diraih sebelumnya.

Berdasarkan survei TIMSS (Trensd in International Mathematics and Science Study) untuk matematika pada tahun 2015, lebih dari $50 \%$ siswa Indonesia berada di level below low dan 30\%siswa berada di level low (Rahmawati, 2015, hal. 20) Rata-rata persentase yang paling rendah adalah domain kognitif yang menempatkan Indonesia pada urutan ke 45 dari 50 negara dengan skor ratarata 397. Hal ini menunjukan bahwa kompetensi matematis terutama kemampuan pemecahan masalah matematis siswa masih rendah, untuk menyelesaikan masalah ini, maka praktisi pendidikan matematika perlu mencari berbagai alternatif solusi yang baik agarkualitas pembelajaran matematika dapat diperbaiki, sehingga melalui kemungkinankemungkinan solusi yang dikembangkan diharapkan dapat membantu meningkatkan kemampuan pemecahan masalah.

Dalam pengalaman lapangan yang dialami oleh penulis di SMP Negeri 3 Kupang Tengah terlihat bahwa prestasi belajar matematika siswa masih rendah, siswa kurang mengoptimalkan potensi yang dimiliki untuk melakukan pembelajaran dengan baik. Siswa beranggapan bahwa dalam menyelesaikan masalah, cukup memilih prosedur penyelesaian yang sesuai dengan

\section{Metode Penelitian}

Jenis penelitian ini adalah penelitian kuantitatif. Desain eksperimen yang digunakan adalah one grouppretestposttestdesign

Tabel 1. Desain Penelitian

\begin{tabular}{cccc}
\hline Sampel & Pretest & Perlakuan & Posttest \\
\hline 1 & $0_{1}$ & $\mathrm{X}$ & $0_{2}$ \\
\hline \multicolumn{4}{c}{ (Sugiyono, 2008, hal. 126) }
\end{tabular}

Penelitian ini dilaksanakan di kelas VII SMPN Kupang Tengah, penelitian ini dilaksanakan pada semester ganjil tahun pelajaran 2018/2019. Populasi dalam penelitian ini yaitu seluruh siswa kelas VII SMPN Kupang Tengah.Sampel penelitian ini adalah satu kelas yang diambil secara acak dengan menggunakan teknik simple random sampling. Teknik pengumpulan data yang digunakan dalam penelitian ini berupa observasi dan tes. Observasi dilakukan oleh dua orang pengamat untuk mengetahui kondisi lingkungan belajar siswa, melihat aktivitas pembelajaran guru dan siswa khususnya mengenai model pembelajaran Open-Ended yang diterapkan. Tes 
dilaksanakan berbentuk uraian dengan jumlah soal 2 nomor. Tes ini digunakan untuk melihat seberapa jauh siswa mampu menggunakan pengetahuan yang telah dimiliki.

\section{Hasil Penelitian dan Pembahasan}

\section{Hasil}

\section{Analisis Data Kuantitatif}

Skor capaian indikator pelaksanaan pembelajaran dengan menerapkan Model pembelajaran Open-Ended terhadap prestasi belajar dapat dilihat pada tabel berikut:

Tabel 2. Capian Indikator Pelaksanaan Pembelajaran

\begin{tabular}{llll}
\hline $\begin{array}{l}\text { Perte } \\
\text { muan }\end{array}$ & $\sum_{\text {Pengamat }}$ skor & $\begin{array}{l}\text { Pengamat } \\
\mathbf{1}\end{array}$ & $\begin{array}{l}\text { Capaian } \\
\text { Indikato } \\
\text { r (CI \%) }\end{array}$ \\
\hline 1 & 69 & 70 & $\frac{139}{150} \times 100$ \\
& & $=92,6$ \\
\hline $\mathbf{2}$ & 73 & 72 & $\frac{145}{150} \times 100$ \\
& & & $=96,6$ \\
\hline & Rata-rata & & $92,6+96,6$ \\
& & $=\frac{189,2}{2}$ \\
& & $=94,2$ \\
& &
\end{tabular}

Berdasarkan tabel di atas maka diagram indikator pencapaiannya sebagai berikut :

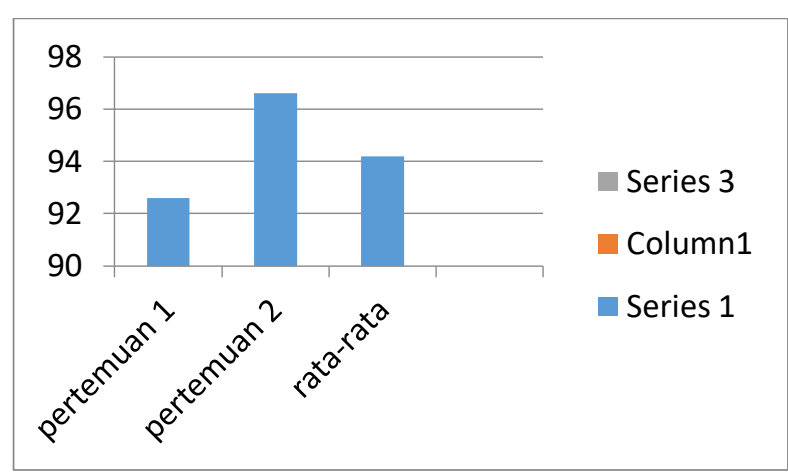

Gambar 1. Capaian Indikator Pencapaian Pembelajaran

Berdasarkan diagram diatas dapat dijelaskan kriteria pelaksanaan pembelajaran dengan menggunakan model pembelajaran Open-Ended untuk setiap pertemuan yaitu:

1. Pertemuan 1, capaian indicator yang diperoleh sebesar 92,6\%, berdasarkan kriteria pada tabel 3.2, maka pelaksanaan pembelajaran dengan menggunakan pembelajaran OpenEnded pada pembelajaran pertama tergolong sangat baik.

2. Pertemuan, capaian indicator yang diperoleh sebesar 96,6\%, berdasarkan kriteria pada tabel 3.2, maka pelaksanaan pembelajaran dengan menggunakan pembelajaran OpenEnded pada pembelajaran pertama tergolong sangat baik.

3. Rata-rata capaian indikator untuk pertemuan 1 dan 2 diperoleh nilai sebelasar 94,6. Maka pelaksanaan pembelajaran dengan menggunakan Pembelajaran Open-Endedpada pembelajaran 1 dan 2 tergolong sangat baik.

Berdasarkan penjelasan diatas, bahwa pelaksanaan pembelajaran dengan menggunakan pembelajaran Open-Ended pada pokok bahasan SegiEmpat dikelas VII SMP Negri 3 Kupang Tengah Tahun ajaran 2018/2019, Tergolong sangat baik, Sehingga 
dapat disimpulkan bahwa kegiatan guru dalam mengelola pembelajaran sesuai dengan RPP yang telah disiapkan.

\section{Analisis Statistik}

\section{Uji Normalitas}

Hasil analisis SPSS untuk uji normalitas pada data pretest dengan $\alpha=0,05$ diperoleh nilai Asymp.Sig. (2-Tailed) $=0.099$ dan $\mathrm{D}_{\text {hitung }}=$ $0,173 \leq \mathrm{D}_{\text {tabel }}=0,294$. Dengan demikiandapat disimpulkan bahwa $\mathrm{H}_{0}$ diterima yang berarti data berdistribusi normal sedangkan untuk data posttes diperoleh uji normalitas dengan $\alpha$ $=0,05$ diperoleh nilai Asymp.Sig. (2-Tailed $)=$ 0.200 dan $D_{\text {hitung }}=0,115 \leq D_{\text {tabel }}=0,294$. Dengan demikiandapat disimpulkan bahwa $\mathrm{H}_{0}$ diterima yang berarti data berdistribusi normal

Uji Hipotesis

Hasil analisis SPSS untuk uji t diperoleh nilai sig. (2-tailend) $=0,000$ (lampiran 10). Sedangkan $t_{\text {hitung }}=10,742$ (lampiran 10), dengan $d f=\mathrm{n}-1$, diperoleh $d f=20$ dengan taraf signifikan $\frac{\alpha}{2}=0,025$ diperoleh $t_{\text {tabel }}=2,085$. Sig. (2-tailend) $=0,000<0,05=\alpha$ dan $t_{\text {hitung }}=$ $10,742>2,085=t_{\text {tabel }}$ (lampiran 10). Berdasarkan hasil analisis uji t dan kriteria penerimaan dan penolakan $\mathrm{H}_{\mathrm{o}}$ dengan tafar signifikan $5 \%$ maka tolak $\mathrm{H}_{0}$ dan terima $\mathrm{H}_{\alpha}$ yang berarti ada pengaruh yang signifikan penggunaan model pembelajaran Open-ended terhadap prestasi belar matematika.

\section{Pembahasan}

Perkembangan Ilmu Pengetahuan dan Teknologi (IPTEK) membawa perubahan yang besar dalam berbagai aspek kehidupan manusia, salah satunya dalam bidang pendidikan.

Guru memiliki peranan penting dalam pendidikan. Hal ini dikarenakan guru merupakan ujung tombak yang berhubungan langsung dengan siswa sebagai subjek.Sebagai seorang guru harus mampu menemukan cara yang tepat dalam proses pembelajarannya.Sehingga siswa dapat meningkatkan prestasi belajarnya.

Menurut Susanto secara sederhana prestasi belajar adalah kemampuan yang diperoleh anak setelah mela kukan kegiatan belajar. Karena belajar itu sendiri merupakan perubahan tingkah laku.

Menurut peneliti lain atau peneliti terdahulu yang dimaksud dengan model pembelajaran Open-Ended adalah sekelompok siswa yang telah tuntas terhadap bahan pelajarannya yang mampu membantu siswa yang mengalami kesulitan belajar.

Berdasarkan uraian diatas, maka penulis tertarik untuk melakukan penelitian dengan judul “ Pengaruh pembelajaran Open-Ended terhadap prestasi belajar matematika pada siswa SMP "

Pada penelitian ini peneliti menjadikan siswa kelas VII SMPN 3 Kupang Tengah sebagai sampel. Proses pembelajarannya menerapkan model pembelajaran Open-Ended dan penulis bertindak sebagai pengajar. Jumlah pertemuan yang dilakukan pada penelitian ini sebanyak 4 kali, dengan rincian 1 kali pelaksanaan pretest, 2 kali proses belajar mengajar dan 1 kali pelaksanaan posttest.

Permasalahan yang dibahas dalam penelitian ini adalah pengaruh model pembelajaran Open-Ended terhadap prestasi belajar siswa kelas VII SMPN 3 Kupang Tengah pada materi SegiEmpat.Penelitian ini hanya meneliti dari segi kognitifnya yaitu dalam bentuk tes yang berisi pertanyaan untuk mengukur prestasi belajar siswa.

Setelah dilakukan pengolahan data skor pretest dan posttest pada siswa terlihat bahwa rata-rata skor postest lebih besar dari pada 
pretest. Berdasarkan perhitungan data dapat dikatakan bahwa model pembelajaran OpenEnded dapat mempengaruhi prestasi belajar siswa kelas VII SMPN 3 Kupang Tengah pada materi Segiempat.

\section{Simpulan dan Saran}

\section{Simpulan}

Berdasarkan hasil penelitiaan yang dilkukan diperoleh hasil sebagai berikut : Pelaksanaan pembelajaran dengan pembelajaran OpenEnded pada pokok bahasan Segiempat di SMP Negri 3 Kupang Tengah tahun pelajaran 2018/2019. Prestasi belajar matematika dengan pembelajaran Open-Ended pada pokok bahasan Segiempat di SMP Negri 3 Kupang Tengah tahun pelajaran 2018/2019.Ada pengaruh yang signifikan pada dpenerapan pembelajaran Open-Ended pada pokok bahasan Segiempat di SMP Negri 3 Kupang Tengah tahun pelajaran 2018/2019.

\section{Saran}

Berdasarkan hasil penelitian yang di lakukan pada mata pelajaran matematika kelas VII pokok bahasan Sistem persamaan linier dua variabel tahun ajaran 2018/2019 maka peneliti memberikan rekomendasi sebagai berikut: Bagi guru dan calon guru matematika agar dapat menggunakan model pembelajaran Open-Ended, sehingga siswa terlibat aktif dan kreatif dalam proses pembeljaran. Bagi siswa agar dapat meningkatkan prestasi belajar matematika dalam pembelajaran. Bagi sekolah mengoptimalkan pemanfaatan model pembelajaran Open-Ended dalam rangka perbaikan dan peningkatan mutu pembelajaran khususnya mata pelajaran matematika.

\section{Daftar Pustaka}

Anonim. (2007). Kamus Besar Indonesia. Jakarta: Dapertemen Pendidikan Nasional Balai Pustaka.

Anurrahman. (2011). Belajar dan Pembelajaran. Yogyakarta : Ar-Ruzz Media.

Arifin, Z. (2012). Penelitian Pendidikan Metode dan Paradigma Baru. Bandung: Remaja Rosda Karya.

Arikunto. (2010). Prosedur Penelitian

Suatu Pendekatan Praktik. JakartaRineka Cipta.

Handul, G. (2003). pengaruh motivasi belajar siswa terhadap prestasi belajar IPA di SD . Jurnal Pendidikan . dipetik februari 28, 2019, dari http/www.acdemia.edu/download 3596857218gludam handul pdf

Huda, M. (2006). Model-model Pengajaran dan pembelajaran. Yogyakarta: Kencana Media grup.

Mudzakir. (1997). Psikologi Pendidikan. Bandung: Pustaka setia.

Rahmawati. (2015). 20. Dipetik desember $\quad 14, \quad 2016, \quad$ dari http//puspendik.kemendikbud.go.id/seminar/ Rahmawati-

Seminar\%20Hasil\%20TIMSS\%202015.pdf: http//puspendik.kemendikbud.go.id/seminar/ Rahmawati-

Seminar\%20Hasil\%20TIMSS\%202015.pdf

Rusman. (2012). Model-Model Pembelajaran. Depok: PT Rajagrafindo Persada.

Sugiyono. (2008). Metode Penelitian Pendidikan. Bandung: Alfabeta.

Suryabata. (1998). Hubungan antara kecerdasan emosional dengan prestasi belajar pada siswa. Skripsi psikologi . Dipetik maret 5, 2019, dari http/www.acdemia. edu/download/31517807//skripsi psikologi 121211021851 phpapp02.doxx 
Suherman, E. d. (2003). Strategi

Pembelajaran Matematika. Bandung: UPI.

Swada. (1997). The open-ended

aporoach a new proposal for teaching

mathematics. Dalam J. d. Becker. virginia. 